\title{
On the use of an instrumented set-up to characterize the impact behaviour of an epoxy system containing varying fly ash content
}

\author{
Kishore *, S.M. Kulkarni, S. Sharathchandra, D. Sunil \\ Polymer Composites Laboratory, Department of Metallurgy, Indian Institute of Science, Bangalore 560012 , India
}

Received 3 November 2001; accepted 14 January 2002

\begin{abstract}
The impact response of a varying fly ash bearing epoxy system was studied. It is observed that with the increase in filler volume fraction there is a net reduction in the impact strength, fracture area and time to maximum load. The Ductility Index of the system, on the other hand, shows an increase with filler level. From visual observations on the failed samples, analyses of the crack length, shift of crack and point at which the slope of the crack reaches $45^{\circ}$ are made. The work clearly shows that a curvilinear path for the crack gives place to straighter ones as the ash content in the matrix increases. Consequently, the crack shift also gets reduced when filler particles are introduced in larger quantities into the resinous system. The SEM pictures unambiguously demonstrate how the initiation, propagation and termination regions have distinct appearances whose features vary with ash content, thereby demonstrating that ash particles do influence the crack at all stages, viz., from its development to final rupture of the test coupon due to impact. The work also throws light on the larger-sized particles playing a role in the furtherance of the crack progression. (c) 2002 Elsevier Science Ltd. All rights reserved.
\end{abstract}

Keywords: Epoxy; Flyash; Impact behaviour; Crack path stages

\section{Introduction}

Successful products in any economy are the ones which display good and lasting performance at low cost. Hence, there is a constant urge and sustained effort to decrease costs and enhance properties of the final product in any manufacturing industry. Demands on improved processability and upgraded performance have stimulated tremendous growth in research in newer materials amongst which polymer composites occupy a prime spot.

Among the topics in the area of development of new materials, modification of polymers with fillers has

\footnotetext{
* Corresponding author. Tel.: +91-80-309-2259; fax: +9180-360-0472.

E-mail address: balkis@metalrg.iisc.ernet.in ( Kishore).
}

gained a prominent position owing to the wide choice available from a host of minerals [1,2], inorganic [3-5], organic [6,7]ceramic materials [8] to act as fillers. There are equally large numbers of choices available for polymeric material systems, from thermoplastics, thermosets and elastomers as matrices. Fillers like fly ash $[9,10]$, sawdust [11], sand [12], talc [13], chalk [14], mica [15] etc, all considered as inexpensive materials, have been used in quite a few of the above-listed matrix systems. Properties of such filled polymer composites can be altered by changing parameters like shape, size, volume fraction and modification of the filler surface by chemical treatments. The need for lightweight materials with high strength and stiffness has led to the development of fly ash based composites. Among the matrix materials, epoxy occupies a prime place owing to its versatile properties like low shrinkage, ease of processing, good wetting of fillers by resin etc. Fly ash, considered a major 
industrial waste product in thermal power plants and having problems of disposal as it is often considered a pollutant, needs an outlet for effective utilization. Epoxy based materials offer a prospective base system for using the ash as a filler.

Although such composites perform quite ably in static tests, when it comes to a dynamic situation the same behaviour may not be seen owing to variety of factors. An important concern in the use of filled composites is the occurrence of defects and damage, either in the processing or in application of the composite, where a nonmonitored or inadvertent impact damage could occur. Therefore, the damage tolerance of promising, filled composites has been a major concern needing study, as published literature on this topic is scant [16].

This work looks first at the utility of an instrumented impact set-up to characterize the impact behaviour of an epoxy system without and with varying fly ash content and thereafter attempts to correlate the mechanical data with visual and scanning electron micrographic observations made on the failed specimens.

\section{Experimental}

\subsection{Materials}

The matrix system consists of a medium viscosity DGEBA epoxy resin (LAPOX L-12) and a room temperature curing hardener with a tetra-amine functional group (K-6) supplied by ATUL India Ltd. The density of cured neat resin was found to be $1120 \mathrm{~kg} / \mathrm{m}^{3}$. The filler used, i.e. fly ash, was obtained from Neyveli Lignite Corporation Ltd., Neyveli (India). This ASTM class 'C' fly ash with bulk density of about $900 \mathrm{~kg} / \mathrm{m}^{3}$ is found to consist of a mixture of solid and hollow spheres of assorted sizes. Particle size distribution of this fly ash, as determined by the Malvern make laser light particle size analyser, consists of two distinct clusters emphasizing a gross bimodal nature [17]. Energy dispersive spectroscopy of the fly ash sample revealed the main constituents to be silica and alumina of about 63 and 26\%, respectively, while traces of other oxides chiefly $\mathrm{Fe}_{2} \mathrm{O}_{3}$ $(7 \%)$ and $\mathrm{TiO}_{2}(2.5 \%)$ were also noticed.

\subsection{Processing}

A measured quantity of epoxy resin was mixed with a pre-weighed amount of fly ash and the hardener was added to this with gentle stirring in order to minimize the formation of air bubbles. The mould for specimen preparation was $320 \mathrm{~mm} \times 170 \mathrm{~mm} \times 3 \mathrm{~mm}$ and completely covered on all sides with Teflon sheet with a coating of silicone releasing agent for easy removal of the cast specimen. The mixture was then slowly decanted into this mould. The mixture was left to cure at room tem- perature for about 24-26 h. The cured rigid plate sample was withdrawn form the mould and the edges trimmed. In this way epoxy based systems with varying amounts of filler were cast. These are listed in Table 1, where other experimentally observed data are also included.

\subsection{Impact testing}

The unnotched impact test samples of dimension 50 $\mathrm{mm} \times 10 \mathrm{~mm} \times 3 \mathrm{~mm}$ were cut from the trimmed cast specimens using a diamond-tipped cutting machine to produce a smooth surface finish. This geometry of test coupons does not conform to ASTM specifications but relative comparison of performance was envisaged in this study. Impact tests were conducted on a Tinius Olsen, pendulum type, universal impact tester model 84 in a Charpy type configuration. Impacts were done on one face of the thickness with the width face resting on the flat end supports. The pendulum with a mass of 27 $\mathrm{kg}$, could provide a maximum energy of $8.2 \mathrm{~J}$ at a maximum velocity of $0.8 \mathrm{~m} / \mathrm{s}$ when positioned at an angle of 15 degrees and released. The test results provided by the system were in the form of the plots of load and energy vs. time. In each category, a minimum of four samples was tested and the average value was used for analysis. As a comparative evaluation is involved, the data obtained were often normalized with respect to that obtained on a plain epoxy system with no filler.

\subsection{Fractured surface features}

The fractured specimens were scanned for further analysis. The scanned images of the edges of the samples were obtained in Adobe photo deluxe software and later imported to AutoCAD 14 for further investigation. A procedure involving pressing an adhesive tape firmly against the fracture surface was followed to make the best contact possible. The protruding tape edges were then trimmed off. The tape, now firmly making contact with the actual contour of the fracture surface, was lifted and its area measured using a planimeter to assess the fracture surface area of impact failed coupons. Only one of the two fractured surfaces of a sample was subjected to such an analysis. The investigation consisted of finding the total crack length, which in this work is a sum total of the stages of crack growth, i.e. 2 and 3 (schematically illustrated in Fig. 6b), length of stage 2 (i.e. the length of crack after the initiation and before the material fails catastrophically) and shift in crack (schematically illustrated in Fig. 6a, where the apportioning of the above categories of crack lengths are depicted). Also, the point at which the slope of the crack reaches nearly 45 degrees (again schematically represented in Fig. 6a) is determined and thereafter its distance from the end that is subjected to impact (face- 2 of 
Table 1

Composition and parameters concerning crack in the test samples

\begin{tabular}{llllll}
\hline Sample & $\begin{array}{l}\text { Fly ash } \\
\text { content } \\
(\text { vol. \%) }\end{array}$ & Stage 2 $(\mathrm{mm})$ & $\begin{array}{l}\text { Total crack length } \\
(\mathrm{mm}) ; \text { Stages 2-3 }\end{array}$ & $\begin{array}{l}\text { Shift of } \\
\text { crack ' } p \text { ' } \\
(\mathrm{mm})\end{array}$ & \\
\hline NE & Nil & 15.6 & 17.2 & 10.9 & 60.2 \\
FA10 & 10 & 11.7 & 14.4 & 6.3 & 68.6 \\
FA20 & 20 & 11.4 & 14 & 6.1 & 69.3 \\
FA30 & 30 & 9.3 & 11.5 & 2.5 & 78.7 \\
\hline
\end{tabular}

${ }^{a}$ defined schematically in Fig. $6 b$.

${ }^{\mathrm{b}} b$ and $a$ are the lengths as depicted in Fig. 6a.

(a)

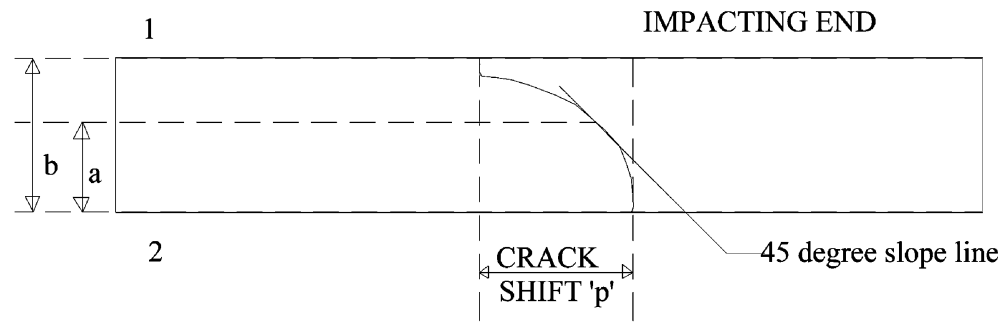

a-Distance from face 2 to the point where 45 degree slope line touches

b- Width of the sample

1-Face of Impact (also where the crack emerges)

2-Face where crack initiates

(b)

IMPACTING END

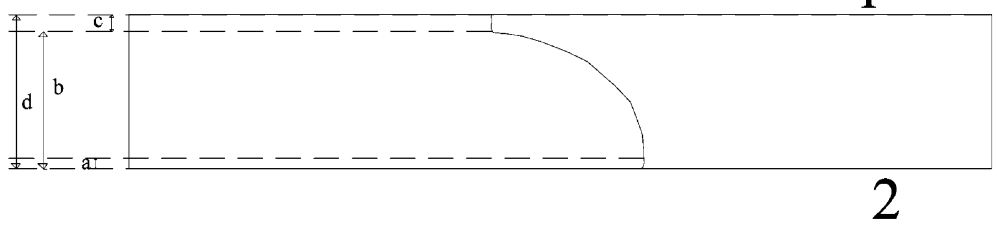

a-Distance of crack initiation from face 2;Stage 1

b-Distance to be measured along curvilinear path of the crack,termed critical crack length (stage 2), that includes initiation stage c-Length of catastrophic failure;Stage 3

d-Distance measured along the curvilinear crack path from face 2 to face 1 i.e. Total crack length

Fig. 6. (a) A schematic showing impacting end (Face 1), crack shift distance ' $p$ ', 45 degree slope line assisting in locating the distance ' $a$ ' from the crack initiation end (face 2) and the total width, ' $b$ '. (b) A schematic showing, $a$-distance corresponding to crack initiation (stage 1), $b$ - the pathway taken by the progressing crack (corresponding to a greater part of stage 2), $c$ - length of catastrophic failure (stage 3 ) where the crack terminates and finally the total crack length distance ' $d$ ' measured along the actual curvilinear path.

Fig. 6a) is measured. The results expressed as percentage distance are also listed in Table 1. 


\subsection{Microscopic characterization}

Samples subjected to impact were examined in a JEOL JSM 840A scanning electron microscope (SEM). The samples were gold coated in an ion sputtering unit beforehand to make them conducting.

\section{Results and discussion}

The energy absorbed by particulate filled polymer composites depends on various aspects such as composition of material, defect or void population, dimensions of the material, debond formed between filler and matrix at the interface. Some of these will be considered while presenting the data from the experiments. In general, the data are presented, as stated earlier, normalized to plain epoxy (i.e. neat ash free resinous material) as a reference.

Fig. 1 shows the variation in normalized load while Fig. 2 represents data on time to maximum load. Figs. 3 and 4 depict, respectively, total energy absorbed and fracture surface area. In all these figures, a general decrement of the respective values with an increase in the level of ash content can be noticed. Fig. 5, which gives Ductility Index (D.I.) [18,19] ,shows an increase with ash content. This index is given by the expression

D.I. $=E_{\mathrm{p}} / E_{\mathrm{i}}$

where, $E_{\mathrm{p}}$ and $E_{\mathrm{i}}$ represent the energies for propagation and initiation and correspond to energies absorbed after and before the maximum load (in the load/energy vs. deflection data given by the instrumented impact setup) respectively.

Fig. 6 schematically represents the crack path from

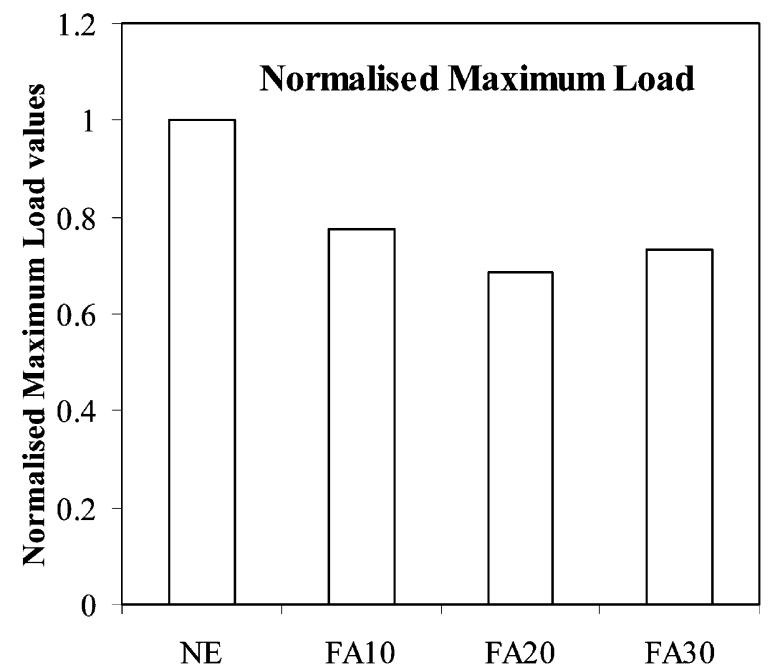

Fig. 1. Bar charts showing the normalized maximum load for various compositions of systems.

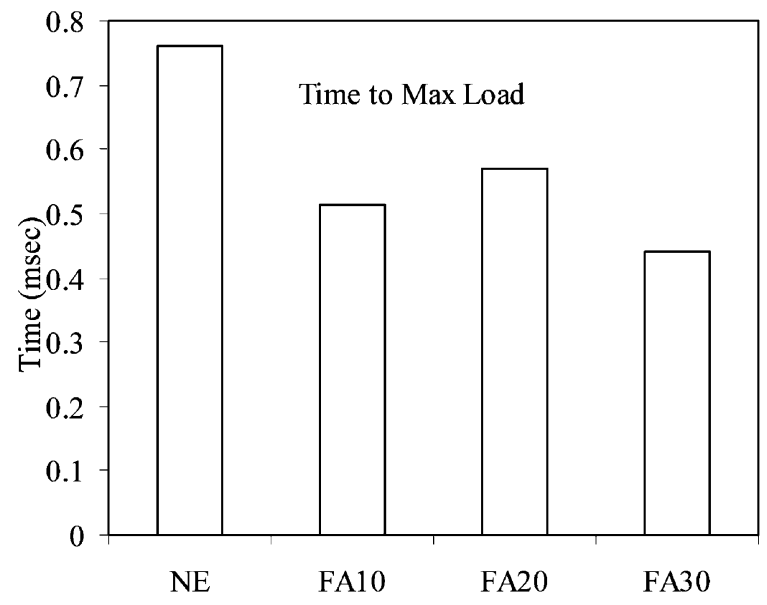

Fig. 2. The variation in time to reach maximum load for different systems.

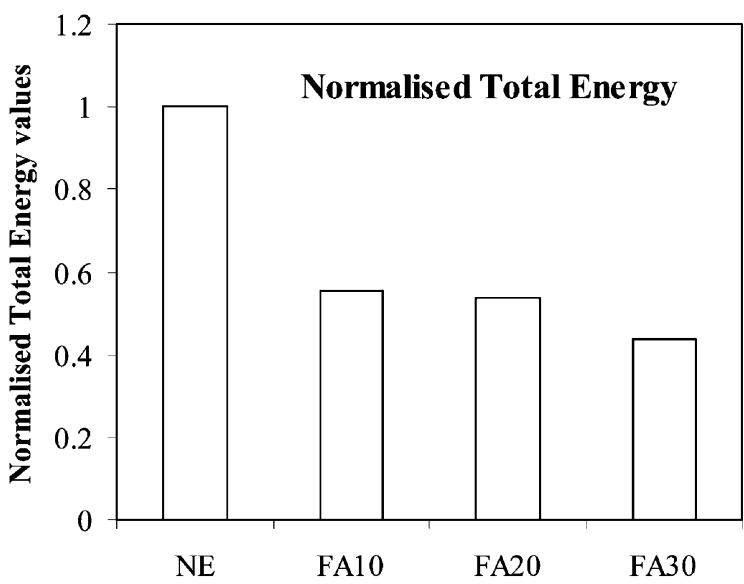

Fig. 3. A plot showing the total energy (normalized) for epoxy system without and with varying amounts of ash content.

initiation on face 2 to its final emergence at face 1 , the impact side, of the test coupon. The apportioning of various stages of crack progression is schematically illustrated in Fig. 6b. The actual situation prevailing in various test samples is progressively illustrated in Fig. 7a$\mathrm{d}$ for ash free to maximum ash ( $30 \%$ by volume) containing samples. From these figures, i.e. Fig. 7a-d, it may be seen that a curvilinear tendency for crack progression is maximum for plain (i.e. flyash free) epoxy while it is least for $30 \%$ ash content. The others (i.e. FA20 and FA10) show midway characteristics. Fig. 6b also shows a schematic picture where stages 1,2 , and 3 of the crack paths are delineated and, in addition, the position where the $45^{\circ}$ angle is recorded. The location of this point in the failed sample was achieved with the help of macrofeatures presented in Fig. $7 \mathrm{a}-\mathrm{d}$. The resulting data are represented as a percentage with respect to distance from 


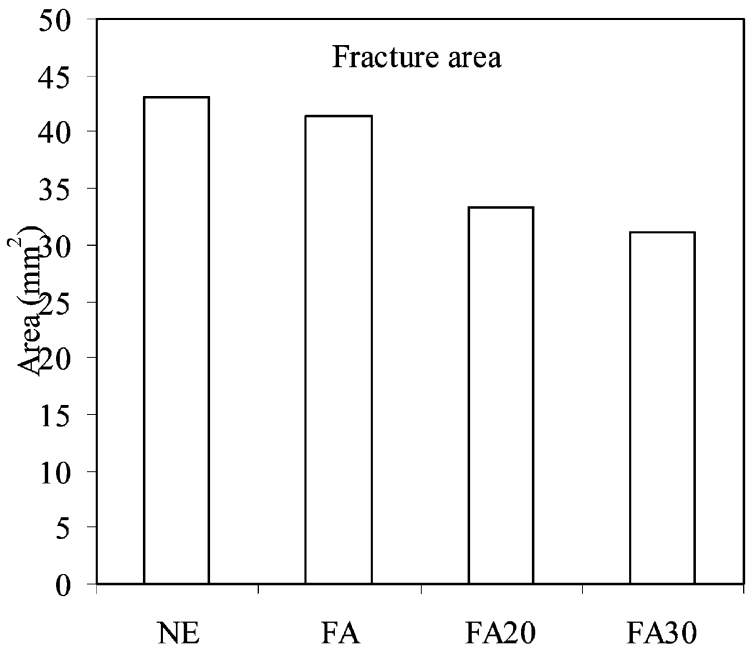

Fig. 4. A bar chart showing the variation in the area of the split surface following impact of the test coupon for different compositions.

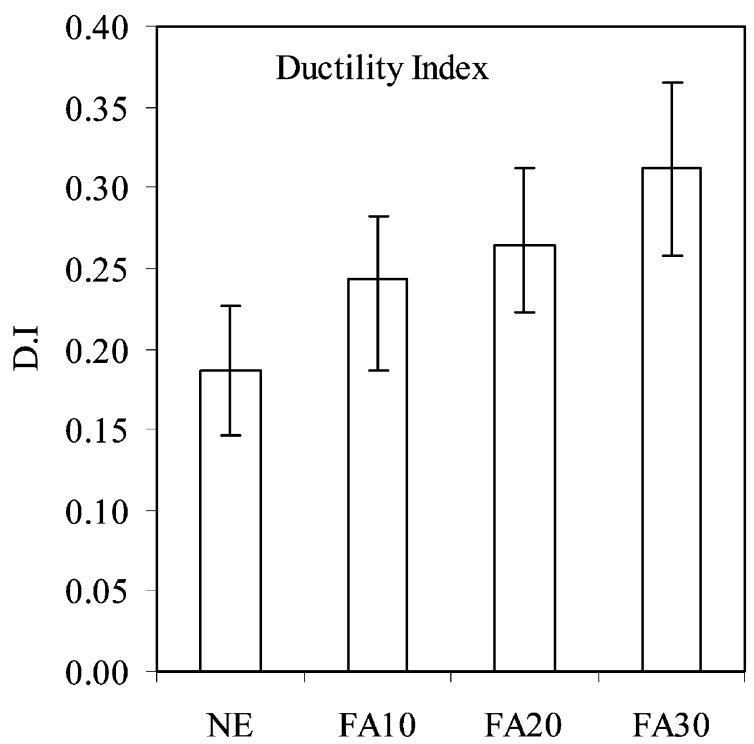

Fig. 5. D.I.s for different systems.

the crack initiation end (i.e. face 2 in Fig. 6a). The data so obtained are also included in Table 1. From this table it is seen that this percentage increases with ash content. Fig. 6a also shows the shift in distance, termed ' $p$ ' in this work, between the starting and emerging regions of the crack. The measured values of these crack shifts, also listed in Table 1, also show a uniform pattern with ash content. To explain why the crack shift and curvilinear path decrease as ash content increases, recourse to fractography has been made and is detailed below.

Fig. 8 is a low magnification picture of the initiation

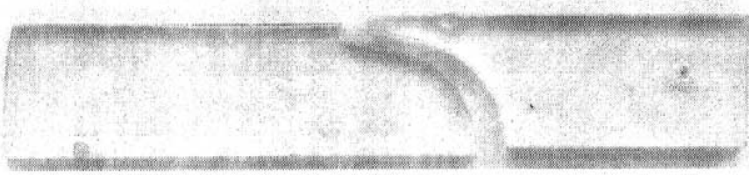

(a)

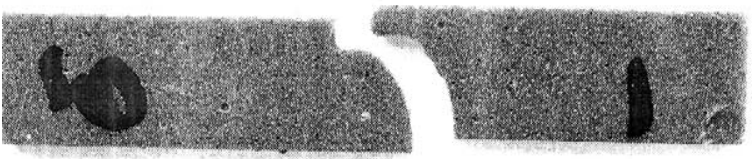

(b)

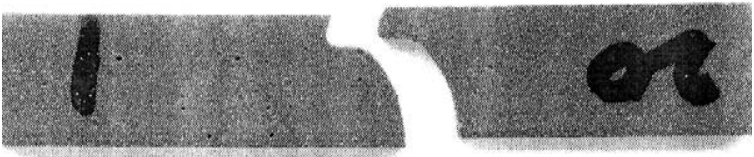

(c)
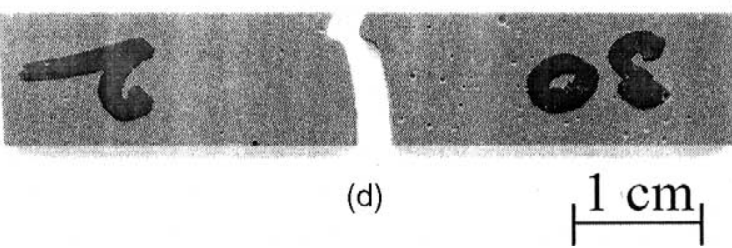

Fig. 7. (a)-(d) A scanning view showing the macroscopic outline of the contour taken by the crack from the initiation to termination. (a) Neat epoxy. (b) FA10. (c) FA20. (d) FA30.

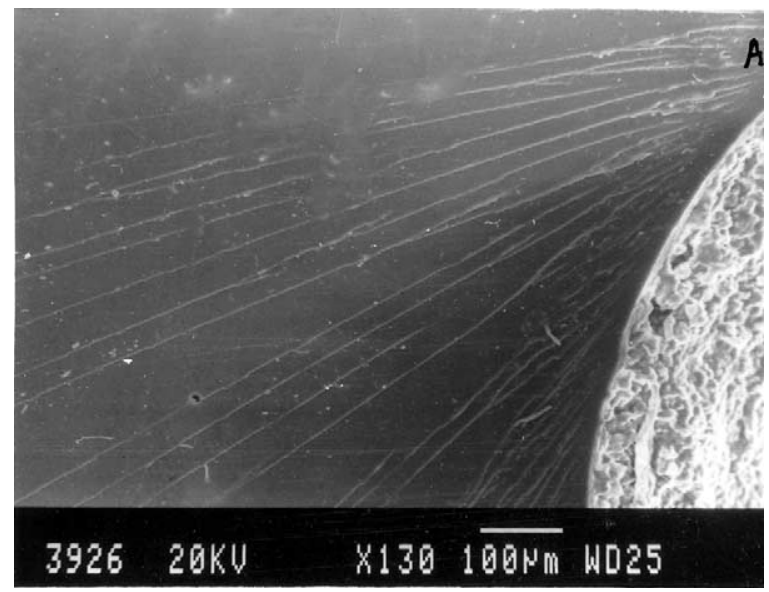

Fig. 8. SEM photograph showing the radial marks emanating from the top-right corner indicating origin in stage 1 for neat epoxy.

part of the neat epoxy where the radial marks indicating the origin can be seen at the top right corner. The radial marks are straight and run by and large without any major interruption. In a similar position (i.e. initiation of crack; i.e. stage 1) for FA30 the initiation point is seen 


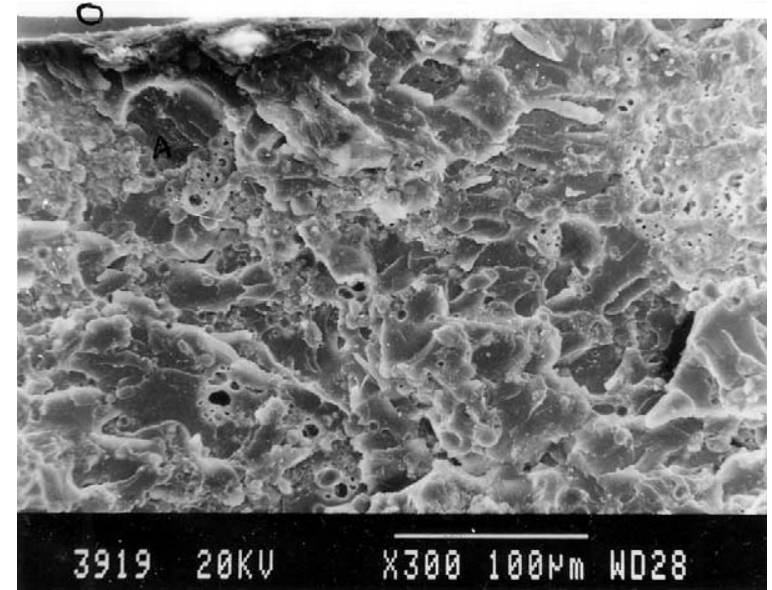

Fig. 9. Features seen in the initiation stage of the FA30 sample.

at a point marked ' $\mathrm{O}$ ' which is to the left of top centre in Fig. 9. Here, the radial marks are less distinctly seen, for instance at ' $\mathrm{A}$ ' compared to the neat epoxy case. This distinguishing feature clearly brings out the effect filler has on the response of the system to impact situations. Having established this difference in appearance for filled FA30 and unfilled neat epoxy near the initiation stage (i.e. stage 1), how the compositional differences results in response changes will be examined now for the propagation stage (i.e. stage 2 of crack; Fig. 6b). Thus, in Fig. 10, which is for the neat epoxy sample, the stepped appearance and the bright appearing regions nearly parallel to one another and running from top to bottom can be seen. The widths of steps, however, are not identical. Under identical conditions, (i.e. stage 2 or the propagation phase) the maximum filler bearing FA30 shows a totally different feature. Here, to the right of the circular

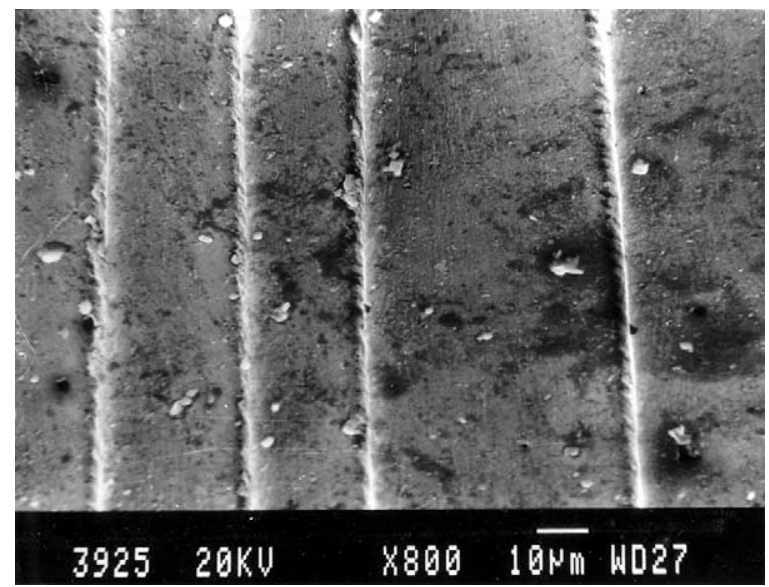

Fig. 10. An SEM fractograph showing stepped appearance of varying width for the neat epoxy in propagation stage.

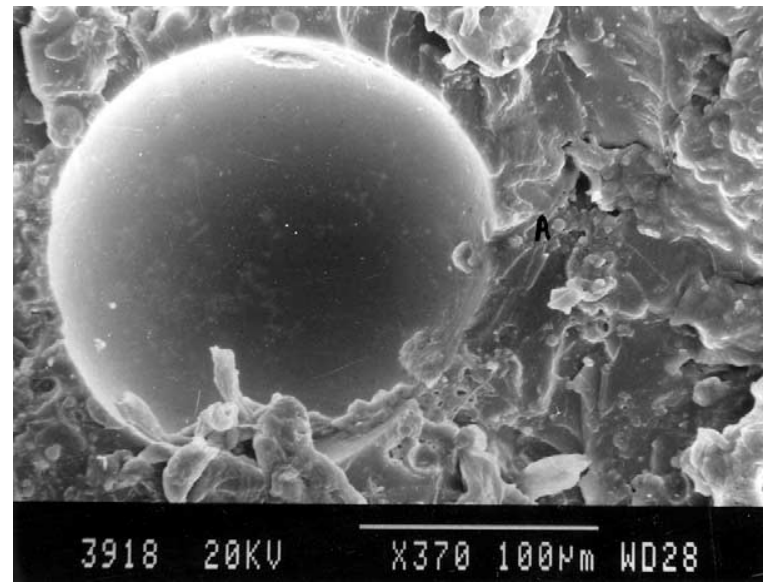

Fig. 11. FA30 showing the matrix features in the propagation phase.

bright patch (Fig. 11 marked 'A') can be seen the faint appearance of these stepped marks of varying width, as in the neat epoxy case. However, the outward fan bladelike features, distinctly seen for neat epoxy (Fig. 8), are less prominent and also discontinuous (Fig. 11). In other words, like in the initiation stage, the presence of ash in epoxy results in less distinct crack propagation features. Also, the lengths of the fan blade like segments are short and discontinuous. This shortening is due to the result of ash particles trying to influence the path of crack progression. To examine this proposition of particle influencing the crack front development, a high magnification picture of FA30 composition is shown in Fig. 12. The cleavage facet and the stepped appearance linking the bigger ash particle 'A' on the left side with what was

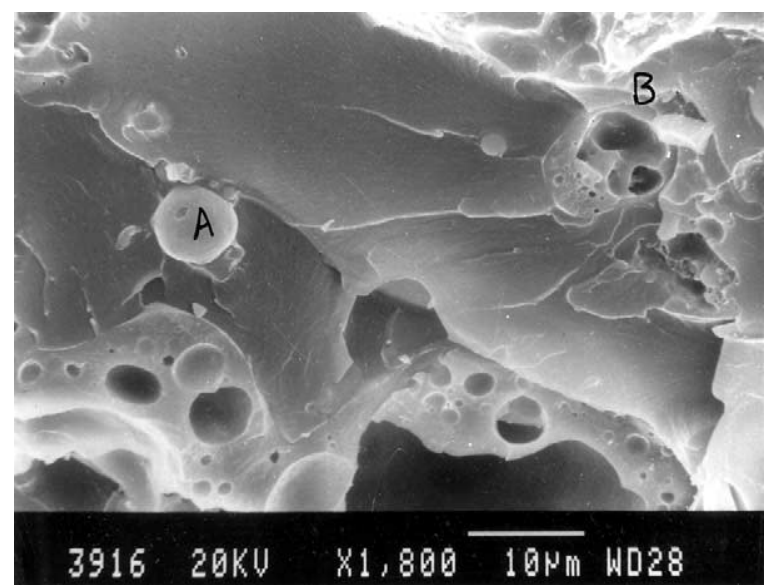

Fig. 12. A high magnification view of FA30 illustrating planes of cleavage and the crack front with one of its arm spread towards 'A' on the left and the other with a cluster of particles ' $\mathrm{B}$ ' on the right. 
originally a cluster of flyash particles at ' $\mathrm{B}$ ' can clearly be seen. In other words, the path of the crack front is demonstrated to be between favourably positioned adjacent particles involving larger-sized ash particles. This role of flyash particles acting as sites for progression of the crack fronts is best illustrated in the FA20 sample for the propagation stage (stage 2; Fig. 6b). Three fronts (marked 1,2, and 3) involving the ash particle marked ' $\mathrm{P}$ ' at the lower end of the photograph and linking with at least one other particle above it can be seen in Fig. 13. The random distribution of ash particles in the epoxy matrix makes such a crack propagation path different from that observed for the neat epoxy case, Fig. 10, where due to the absence of filler, the weakest pockets of the covalently bonded material favour the crack propagation. Consequently, the crack takes no specific direction for the plain epoxy case. On the other hand, for samples involving fillers the direction of impact and presence of larger-sized flyash particles in the path influence the progression of the crack. Ash bearing samples show less distance for the crack to initiate, propagate and finally terminate at the other face of the test coupon as the filler level increases. Thus the work demonstrates that macroscopy and the SEM fractography can ably aid in interpretation of impact data gathered using an instrumented set-up. Further, the difference in performance between neat epoxy and filled particles highlights how ash particles can play a key role both in initiation and propagation stages of the crack progression.

Coming to the last region (segment ' $\mathrm{C}$ ' in Fig. 6b) where the crack emerges on the other side of the test coupon, the following features are seen. Fig. 14 shows the low-magnification picture of the neat epoxy where the 'river' marks are seen distinctly at the lower end.

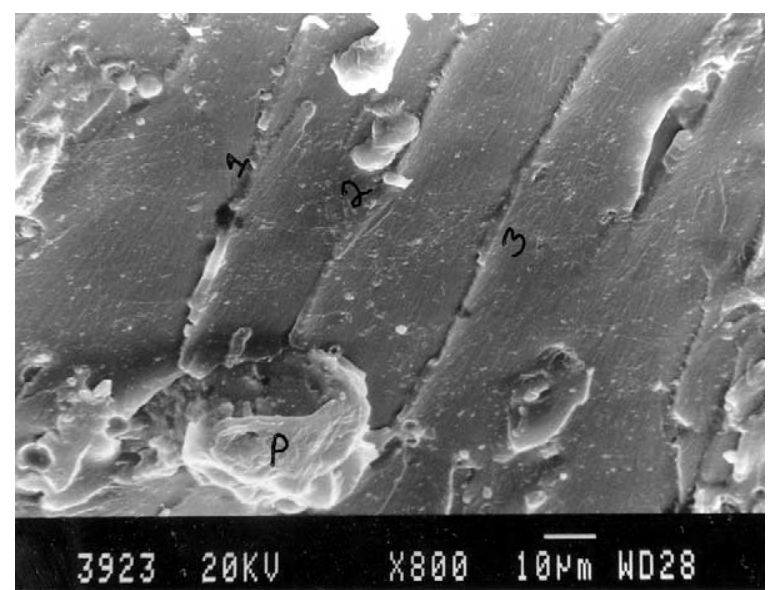

Fig. 13. Propagation phase in FA20 sample (note for the segments marked 1,2, and 3 the bigger particle at lower left centre marked ' $\mathrm{P}$ ' is connected with at least one another ash particle above it).

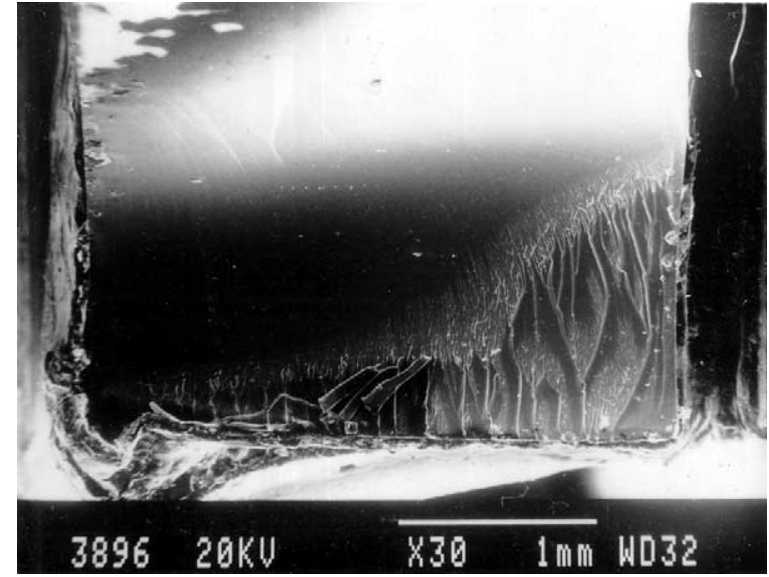

Fig. 14. The termination stage in neat epoxy at low magnification showing a stepped appearance and river pattern.

The stepped appearance at this end is due to the change in the plane of fracture when it approaches the free surface. How the river marks appear at a slightly higher magnification is illustrated in Fig. 15. The low magnification photograph of FA30 is shown in Fig. 16. The difference in features for identical magnifications in this region between this sample and for neat epoxy case shown in Fig. 14 is obvious. The river patterns seen earlier for the neat epoxy case are present to a far reduced extent and appear less distinct. Hence, the ash particles also play a key role in this last stage of crack propagation. To examine the role of ash particles better, a high magnification picture of the sample is shown in Fig. 17, where the debonding and subsequent displacement of larger sized ash particle is clearly seen. In the same photo, the smaller sized particles (marked 'A' and 'B') which are still intact can be seen. This photo clearly sup-

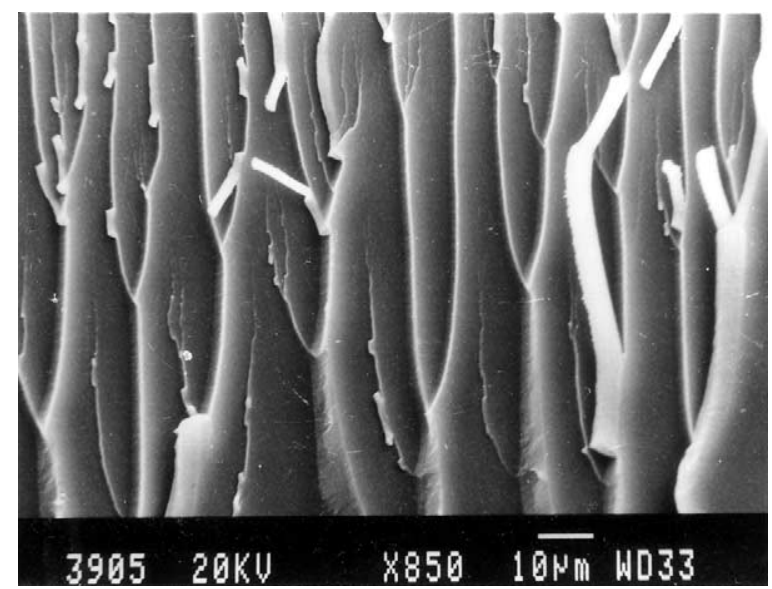

Fig. 15. High magnification view of the above sample highlighting the river pattern. 


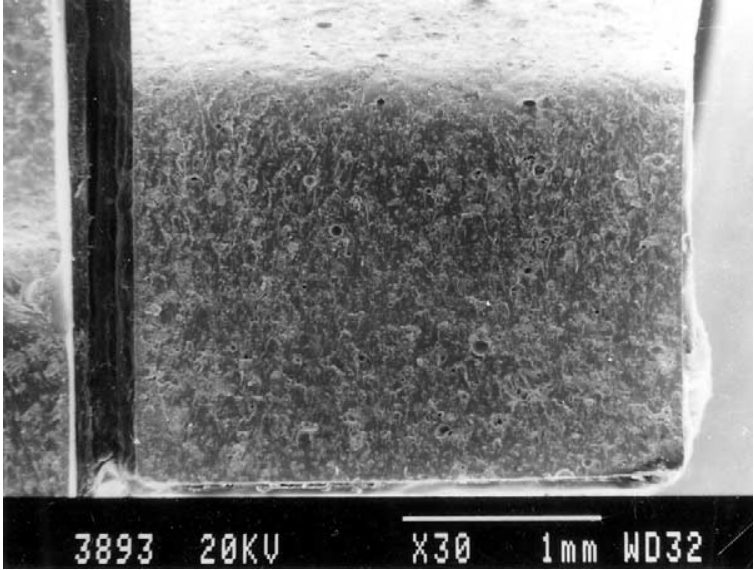

Fig. 16. FA30 sample showing the lack of clear details like in neat epoxy in the termination stage (Fig. 14).

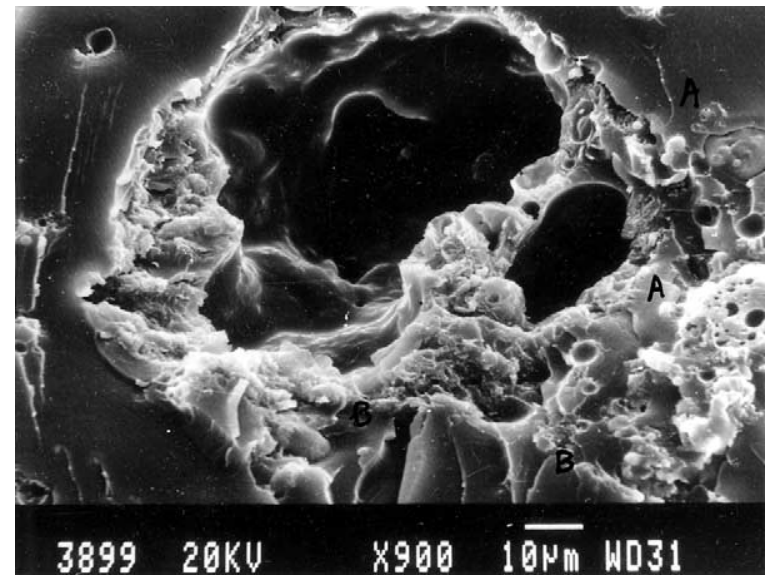

Fig. 17. A SEM surface feature showing the debond and subsequent detachment leading to a dark cavity-like feature in FA30 sample in the termination stage of the crack path. Note the large cavity size emphasizing the debond favoured by larger-sized particles. Also smaller-sized particles marked 'A' and ' $\mathrm{B}$ ' remaining intact in the resinous matrix can be noticed.

ports the statement earlier that debonding is favoured by larger sized particles.

As regards the last stage of crack progression leading to fracture in other ash bearing samples, Fig. 18 shows the river marks features seen in the FA20 sample. Compared to the similar stage in neat epoxy, viz., Fig. 14, they are less defined but the features here are more distinct compared to what was seen in FA30 (Fig. 16). In brief, FA20 displays characteristics in the last stage that are in between neat epoxy and FA30, again corroborating the mechanical test data.

From the above it is seen that in the initial stage (i.e. stage 1) for plain epoxy the origin is distinct and the radial marks travel full distance. Regions having defects

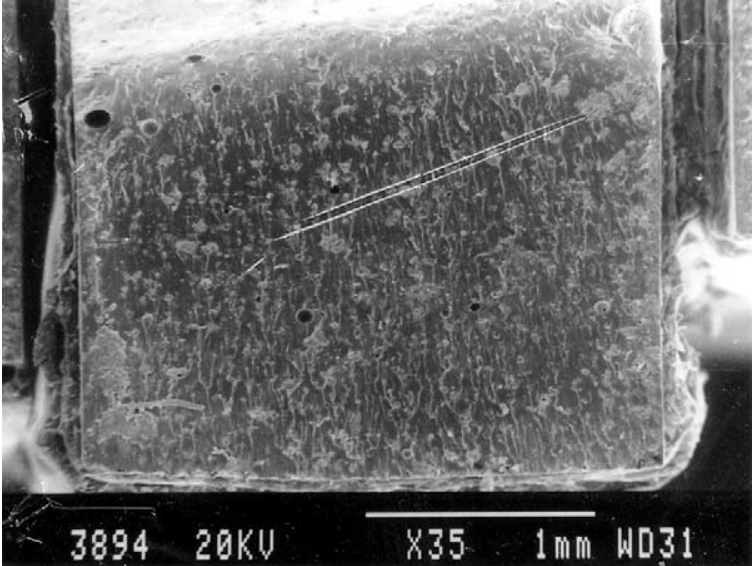

Fig. 18. Features in the termination stage of the FA20 sample. River marks visible on careful scrutiny, though less distinct compared to neat epoxy in Fig. 14 are much clearer here, compared to FA30 in Fig. 16.

and regions of inhomogeneous material distribution, whose occurrence is not regular, act as locations for crack propagation. Consequently, no specific path is chosen for neat epoxy and a curvilinear path is taken for stage 2 (Fig. 6) once initiated at a defect. Stage 2 for this sample shows river marks whose density is higher than in all the other impact-failed samples. The curved nature ensures high energy (Fig. 3) and larger surface area (Fig. 4) for fracture as well as the maximum load absorbed (Fig. 1). The fractographs and the visual macroscopy (Fig. 7a-d) thus correlate well with the mechanical data for neat epoxy.

When FA30 is considered, this shows lower energies and maximum load for both initiation and propagation stages. The debonds, especially at the larger-sized particles whose numbers rise as ash content increases, act as sites for the crack front to extend, thus favouring a shorter path. The SEM photo for ash bearing material (Fig. 13) shows consecutive larger sized ash particles helping in the extension of the crack front branches. Consequently, the crack shift is small and the energy absorbed is reduced compared to neat epoxy. Similarly, the time to maximum load is also lower as each ash particle provides for early initiation in the form of debonds. Also, the higher population of ash favours a straighter crack path thereby reducing the total surface area (Fig. 4) of the split surface of the sample for this composition. However, to explain the higher D.I. for this sample (Fig. 5 ) it must be remembered that this is a ratio of energies for propagation and initiation. The debonds occurring around large ash particle favour early initiation (Fig. 2) but their propagation requires locating the next set of favourably positioned ash particles lying in the path of the impact of the hammer. This results in a delay during which energy is absorbed to a value that is more than 
that required for initiation. This situation, brought more by topographic considerations, enhances the D.I. as ash particle content increases. Values recorded for FA10 and FA20 are between those for FA30 and neat epoxy.

\section{Conclusions}

The above experimental analyses leads to the conclusions that fly ash filled epoxy composites display lower impact strengths with an increase in filler content. Although epoxy absorbs a higher energy of impact it records a lower energy of propagation. On the other hand, filled systems show less initiation energy. The high D.I. of filled systems is attributed to the larger energies involved in the propagation of the crack. Decreases noticed in Stage 2 of total crack length and shift of crack with increase in filler content are attributed to the large sized ash particles favouring debonds and thereby affecting response of the material to impact. The SEM features show that ash particles do influence the crack path at all stages.

\section{Acknowledgements}

All the authors wish to thank Mr Srinivasmurthy, Mr Gurulinga and Mr D. Mollaiah of the Department of Metallurgy for the help rendered by them during testing and inspection of the samples. Third and fourth authors (Sharathchandra and Sunil) wish to express their gratitude to their colleague Bijoysri Khan for helping in getting the scanned pictures.

\section{References}

[1] P. Mareri, S. Bastide, N. Binda, A. Crespy, Mechanical behaviour of polypropylene composites containing fine mineral fibre: effect of filler surface treatment, Compos. Sci. Tech. 58 (1998) 747-752.

[2] Z. Brito, G. Sanchez, Influence of metallic fillers on the thermal and mechanical behaviour in composites of epoxy matrix, Compos. Srtuct. 48 (2000) 79-81.

[3] S. Barta, J. Bielek, P. Dieska, Study of thermophysical and mechanical properties of particulate composite polyethylene- $\mathrm{CaCO}_{3}$, J. Appl. Polym. Sci. 64 (1997) 15251530.
[4] B. Pukanskey, F.H.J. Maurer, Composition dependence of fracture toughness of heterogeneous polymer systems, Polymer 36 (1995) 1617-1625.

[5] M. Hussain, A. Nakahira, S. Nishijima, K. Niihara, Fracture behaviour and fracture toughness of particulate filled epoxy composites, Mater. Lett. 27 (1996) 21-25.

[6] E.J. Queen, in: H.S. Katz, J.V. Milewski (Eds.), Hand Book of Fillers and Reinforcements for Plastics, Van Nostrand, NewYork, 1978, pp. 278-291.

[7] M.L. Karasek, L.H. Strait, M.F. Amateau, J.P. Runt, Effect of temperature and moisture on the impact behaviour of graphite/epoxy composites: part 1-impact energy absorption, J. Compos. Technol. Res. 17 (1995) 3-10.

[8] B.Z. Jang, J.Y. Liau, L.R. Hwang, W.K. Shih, Structureproperty relationships in thermoplastic particulate and ceramic whisker modified epoxy resins, J. Reinf. Plast. Compos. 8/4 (1989) 312-333.

[9] S. Sen, N. Nugay, Uncured and cured state properties of flyash filled unsaturated polyester composites, J. Appl. Polym. Sci. 77/5 (2000) 1126-1136.

[10] V.K. Srivastava, P.S. Shembekar, Tensile and fracture of epoxy resin filled inter flyash particles, J. Mater. Sci. 25 (1990) 3513-3516.

[11] D. Maldas, B.V. Kokta, R.G. Raj, C. Daneaut, Improvement of mechanical properties of sawdust wood fibrepolystyrene composites by chemical treatment, Polymer 29/7 (1988) 1255-1265.

[12] O. Jshai, L.J. Cohen, Elastic properties of filled and porous epoxy composites, Int. J. Mech. Sci. 9 (1967) 539-546.

[13] J.E. Stamhius, Mechanical properties and morphology of polystyrene composite II Effect of polar contents in talcfilled polypropylene, Polym. Compos. 9 (1988) 72-77.

[14] P.H. Vollebberg Th., D. Heikens, Mechanical properties of chalk filled polypropylene: a preliminary investigation, J. Mater. Sci. 25 (1990) 3089-3095.

[15] S.F. Xavier, J.M. Shultz, K. Fredrich, Fracture propagation in particulate filled polypropylene composites Part 2. Influence of mica concentration, J. Mater. Sci. 25 (1990) 2421-2427.

[16] N. Yoshinobu, Y. Micho, O. Masayoshi, Instrumented charpy impact test of epoxy resin filled with irregularshaped silica particles, Polym. Eng. Sci. 33 (1993) 279284.

[17] S.M. Kulkarni, Kishore, Compressive strength of epoxy with bimodal filling of flyash, J. Reinf. Plast. Compos. (in press).

[18] S.B. Driscoll, in: S.L. Kessler, G.C. Adams, S.B. Driscoll, D.R. Ireland (Eds.), Variable-rate Impact Testing of Polymeric Materials—a Review, ASTM STP, 936, ASTM, Philadelphia, 1986, pp. 163-185.

[19] P.W.R. Beaumont, P.G. Riewalid, C. Zweben, Methods for Improving the Impact Resistance of Composite Materials, ASTM STP, 568, 1973, pp. 134-158. 